\title{
Thinking and Practice on the Construction of Signals and Systems Course in Technology Applied University
}

\author{
Wenhong Liu \\ School of Electronic and Information, Shanghai Dianji University, Shanghai, China
}

Email address:

liuwenhong@sdju.edu.cn

\section{To cite this article:}

Wenhong Liu. Thinking and Practice on the Construction of Signals and Systems Course in Technology Applied University. Science Journal of Education. Vol. 4, No. 2, 2016, pp. 101-107. doi: 10.11648/j.sjedu.20160402.23

Received: April 29, 2016; Accepted: May 16, 2016; Published: May 19, 2016

\begin{abstract}
Signals and systems is a very important professional basic course in electronic information specialty. Based on the position of technology applied university, in this paper, the signals and systems course construction is planned, the relationship and interaction between theory and practice teaching are thought, and the course construction goal, content, principle, method, practice process and characteristics are presented. This course construction can improve the teaching effect. First, students can be in a deep understanding and grasp the signal expression and system description. Second, they improve abilities of the analysis and solving problems through computer simulations and practical application cases. What's more, learning signals and systems course well makes students have a solid foundation for learning the following courses and being engaged the electronic information technology development and application.
\end{abstract}

Keywords: Signals and Systems, Technology Applied University, Course Construction, Thinking and Practice

\section{Introduction}

Signals and systems course is related to quite broad professional areas. It belongs to a major basic course of a large class of disciplines and is one of the compulsory subjects of related professional graduate student entrance examination. Signals and systems course prerequisite courses are higher mathematics course, engineering mathematics course, circuit analysis basis course, in parallel with the analog electronic technology course, digital electronic technology course, and the subsequent courses are digital signal processing course, signal analysis and application course.

Although the core content of signals and systems course is similar in each university, the application background, teaching objectives, and teaching requirements in different level universities, or different professional in the same university vary. What' more, teaching methods and application cases will have corresponding differences.

In this paper, based on the position of technology applied university, the signals and systems course construction is planned, the relationship and interaction between theory and practice teaching are thought, and the course construction goal, content, principle, method, practice process and characteristics are presented.

This course construction can improve the teaching effect. Students can be in a deep understanding and grasp the signal expression and system description. They improve abilities of the analysis and solving problems through computer simulations and practical application cases. What's more, learning signals and systems course well makes students have a solid foundation for learning the following courses and being engaged the electronic information technology development and application.

\section{Thinking on the Construction of Signals and Systems Course}

\subsection{The Signals and Systems Course Construction Significance}

Some professional foundation courses, such as the circuit analysis basis, signal and system, the analog electronic technology, digital electronic technology" and so on, relates to the areas of professional and quite broad, belongs to the discipline of related to a large class of major basic courses. 
Although the core content is similar, but different application background of specific requirements, the application of case teaching is not a small difference.

This topic for oriented school faculties School of electronics and information engineering, electrical engineering, automobile, etc., offering multiple electronic and information engineering, communication engineering, computer technology and application, network engineering, networking, automation, vehicle engineering, vehicle engineering, etc. major professional foundation course group, on the basis of circuit analysis, signal and system, the digital signal processing for the vertical axis, with various professional as the horizontal axis, with both the professional core curriculum of signal and system as the center, wide professional basic course group teaching research, reform and practice.

The signal and system course prerequisite is higher mathematic, Engineering Mathematic, circuit analysis, in parallel with the course analog electronic technology, digital electronic technology, the follow-up course is digital signal processing, the signal analysis and application, this course for the undergraduates majoring in electronic information, communication, network, automatic control, vehicle engineering discipline core foundation courses and related professional graduate students entrance examination of one of the compulsory subjects. Department of electronic and Information Engineering College of electronic information, undertake electrical engineering, automotive engineering and other relevant professional teaching tasks. This semester has eight teachers for 10 class teaching of this course.

In common with most engineering courses, the course of signal and system is the basic course for electronic information specialty, also originated in Europe and the United states. In the fifties of the 20th century, Massachusetts Science Institute of technology summary since the Second World War in the field of communication, radar and control widely used theory, signals and systems course and teaching convolution, Fourier transform, Laplace transform, feedback analysis, and other professional knowledge.

Although in the seventies of the 20th century, Massachusetts Institute of technology of this course to join the system state machine, numerical analysis methods and so on, but failed to elicit a response, the mainstream teaching still use the original teaching content.

In modern China, the teaching system and content are relatively backward, until after the cultural revolution, China to open the signal and system course, and invested more in the course of construction, rapid development, materials and more and more, but teaching is still the core in three transform, Fourier transform, Laplace transform, $\mathrm{Z}$ transform mainly, but mainly in communication engineering and electronic information engineering colleges and universities will join the state space description of explain in detail and in the subsequent process of teaching opened digital signal processing" course.

At present, with the rapid development of information technology, new theories and new technologies continue to emerge, interdisciplinary integration increasingly close, signals and systems is not only core foundation courses for electronic information majors, has also become a automatic control, automotive, vehicle, networks, and other related professional is an important professional basic course. Therefore, the teaching of signals and systems course is also advancing with the times, subject teaching according to the continuous development of technology situation, timely adjustment of training objectives, reform and construction in the course system, teaching contents, teaching methods and experimental means.

At present, the teaching reform of signal and system course is mainly reflected in the following aspects:

Adjust the system of courses, the circuit analysis basis, signal and system and the digital signal processing as a series of courses, optimize the content system of the course series, make system within the curriculum more clear division of labor, such as in circuit analysis basis such as circuit basic theory and analysis method; in signals and systems prominent analysis of continuous time signal; in digital signal processing discrete analysis foundation.

Update teaching content, reduce the basic mathematics knowledge to explain, such as Fourier transform; the digital signal processing course of DFT, DFS based content moved to the signal and system course; the teaching focus on the physical connotation of the signal and system, increase the project case, theory and practice combination.

Change the teaching method, the traditional teaching method combines the small class teaching, the classroom teacher, the question discussion class, the classroom instruction and the network teaching unifies and so on the teaching means. It is found that the students are weak in the understanding of the knowledge in the classroom and the discussion class, which improves the students' learning interest and learning initiative.

The reform of experimental teaching method, on the basis of traditional DSP experimental box, the introduction of $\mathrm{C}$ language and MATLAB of the signal and system of simulation software, demonstration experiment of a single extended to from the point to the transition surface of the comprehensive and self design a combination of experimental model, enrich the content of experiment teaching, strengthen students' ability of design, and the abstract concept of a deep understanding of signal and system.

The subject group for Chinese and other countries colleges and universities mainly studies the status of a professional teaching, combined with the school of electronics and information engineering, communication engineering, networking, network, computer, automation, automotive, vehicles and other professional teaching objectives, focus on specialized basic course of relationship between, clarify the first courses, links between subsequent courses, construct reasonable knowledge learning system; focuses on the generality of the signal and system course and in various professional characteristics, in the common outstanding core content, on the characteristics of outstanding application case of different professional and maintain common at the same 
time, prominent characteristics.

To sum up, to broad fields curriculum group teaching research, reform and practice can improve the teaching level of teachers teaching, help students understand and grasp the core content of the knowledge system and improve their theoretical and practical ability, is conducive to the application and technical colleges professional teaching.

\subsection{Research Objectives, Content, Principles, Methods, Practice and Characteristics}

The clue of this course group is circuit analysis foundation, signal and system, digital signal processing, the core is signal and system. Signals and systems teaching in higher education should be in teaching students the theoretical knowledge, training students theory with practical ability and mastery of signals and systems involved in the basic theory and application in engineering practice to solve practical problems, to learn the theoretical knowledge for the work. At present, major colleges and universities offering signals and systems test course for professional, rather than electronic information engineering professional courses, so in order to meet the many problems of professional teaching, this paper put forward oriented multi professional curriculum system and content of the research.

This paper aims to study to meet the demand in many professional oriented of signal and system teaching mode, on the foundation of theoretical knowledge of learning, focus on highlighting engineering application characteristics of education, emphasizing teaching jobs and the practical application of effective combination to optimize the teaching content according to the needs of the society for technical and theoretical knowledge to the application of professional guidance, training students in the application of signal and system" theoretical knowledge to solve practical engineering problems involved in the professional capability.

The characteristics of this project are mainly reflected in the following three aspects:

On the basis of the basic theory, the development of the specific teaching content is mainly based on the background of each professional demand.

Corresponding to the different professional, the corresponding examples or practical application case into the curriculum teaching, design the corresponding teaching scheme and the teaching method emphasizes more professional, and its application characteristics, stimulate students' enthusiasm for learning, and thus play a subjective initiative, cultivate ability to solve practical problems.

In depth study of the characteristics of each specialty, and according to the characteristics of the corresponding theoretical focus, to achieve this course and professional seamless.

The signal and system course is electronic information engineering professional core courses, but also communication, network, automation and other professional important elective course of, in the rapid development of the information age of today, control and signal processing plays a pivotal role, its application is very wide, from aerospace to the production life, everywhere, and the signal and system course is based. Therefore, this paper intends to formulated to meet the requirements of various professional teaching implementation plan, the specific contents are as follows.

With to meet the needs of the multi professional as the guide to optimize the teaching content. The signal and system course the biggest feature is the theory of strong, involved the leading course more involving calculus, complex variable function, probability theory and mathematical statistics, stochastic process of basic mathematics knowledge, and control theory, communication theory, signal and system also closely related. And because of its strong theoretical system to support the knowledge of the course teaching, with a wide range of applications.

Therefore, in order to adapt to the needs of different professional applications, the project put forward, according to their professional characteristics, theoretical teaching content to do the corresponding adjustment, that is, the theoretical knowledge of the focus is different. Take automation major as an example, in the study of signal and system course, the professional advanced mathematics, linear algebra, complex variable function, circuit theory, electronic technology foundation. Subsequent courses has motor and electric drive, computer principle and interface technology, computer control technology, process control system, microcomputer principle and interface technology, automatic control theory, power electronics, signal and system analysis, the process of detection and instrument and so on.

The professional focus on and the organic combination of electronic engineering, computer science, electrical engineering knowledge, cultivating the ability of students' software programming, debugging and hardware design, production; and train students in computer control system, motor drive and control system, automatic detection system, CNC system and intelligent instrument such as design, development and application of maintenance capacity. Thus it can be seen that signals and systems course and automation professional students follow-up process control system, automatic control theory, signal and system analysis in close contact, so about the theory is the focus adjustment for linear systems and Laplace transform, fully meet the needs of the professional, for its application to lay a solid foundation.

Through the adjustment of the theory of knowledge focus, can make students aware of this study, so as to gradually cultivate students' interest, and finally constructs to "to meet the requirements of various professional" oriented optimization of teaching content of the teaching mode.

The theoretical knowledge to the various professional application guide. Teaching and practical application does not adapt the course on signals and systems in the teaching of the problems generally existing in the course of, to be adapt to the needs of professional, the project to develop, according to the professional characteristics, theoretical knowledge taught to different professional guidance.

Take the automation specialty as an example, for example, when talking about the Laplasse transform, the practical application of the system can be used as an example to analyze 
the system, which allows students to have a more intuitive understanding of the theory. In addition, in order to better the theoretical knowledge to the professional application guide, can also take the following measures:

To integrate the actual project into the curriculum teaching. The actual project into the teaching of signal and system, action oriented and the decomposition of the learning for one specific engineering, design the corresponding teaching scheme, help students to better grasp the theory, but also to the theory and practice. This teaching method emphasizes the development of collaborative learning, self exploration and innovation, and stimulates students' enthusiasm for learning, so as to exert their subjective initiative and cultivate the ability to solve the related practical problems.

In the actual project to introduce the teaching process to pay attention to choose or develop the project must cover the teaching goal of the professional this course involves the teaching content, ability and quality requirements, closely around the optimization of teaching outline, for the project to develop the general task, combined with the focal points on the teaching of each chapter, and different levels of students with the knowledge and ability to effectively complete the task, make a number of sub projects. Sub project development cannot be too difficult, it cannot be too easy, but not too much, the scale should not be too large, to be just right, to help students really grasp the knowledge points, flexible use.

So the teaching tasks completed by top-down form, namely under the general project decomposition for each sub project in the form of to complete, the total project with macro and sub project with microscopic is the relation between the whole and the part. Such as the problem of Fourier transform, we can combined with engineering application background to develop a project, project total can develop for radar signal time-frequency analysis, decomposition into three sub projects, analysis of the discrete time Fourier transform method, discrete Fourier transform method for the analysis, fast Fourier transform analysis, in the implementation process, it is necessary to pay attention to the independence of each of the sub project, but also note the baryon project, and ultimately the formation of the Fourier transform system understanding, and can flexibly.

By the professional and the corresponding practical project into the curriculum teaching method can make the professional students master the knowledge and application of methods in the process to complete the task to apply what they have learned.

The establishment of a number of professional instructors teaching cooperative studio. In order to deeply explore the characteristics of each specialty, and according to the characteristics of the corresponding theoretical focus, to achieve this course and professional seamless docking, the project to develop a multi professional instructors to work in the studio.

The establishment of the studio for students and teachers to teach the course of the teacher. In a studio environment, to the project as the basis, to facilitate communication between students and teachers and teachers, communication, and enable the students to fully understand theory to guide practice, practice can be used to verify the theory, so as to avoid previous theoretical teaching and practice from the phenomenon, narrowing the distance between theory and practice, full and effective use of resources of colleges and universities.

On the platform, combined with the technical requirements of the professional to develop teaching plans, the actual project, in the course of the learning process, the students' and teachers' zero distance contact, easy absorption and transformation of professional knowledge, not only can improve the students' theory, and can cultivate the practice ability.

Teaching methods and means. The project intends to adopt the conventional teaching methods and means, such as teaching method, talking method, demonstration method, practice method, class discussion method, experimental method, etc.

Experimental method is one of the students under the guidance of teachers, the use of certain equipment and materials, by controlling the process of operating conditions, causing certain changes in the subjects, from the observation of these phenomena changes get new knowledge or validating knowledge of teaching methods. And the particularity of the course, the experiment is refers to through the computer simulation, the software MATLAB, the software, students under the guidance of teachers, the simulation of the theory, to understand the knowledge of great benefit.

Course assessment methods. For the course evaluation methods, based on requirements of the school to examine the course, take the examination combined with the examination papers, homework, small papers, research report, hands-on, field operation skills, defense and test and daily performance.

Evaluation system. Curriculum evaluation system uses student evaluation, teacher evaluation, school evaluation, the combination of the three ways, the teaching of the course evaluation. The content of the assessment includes teaching methods, teaching methods, teaching attitude, teaching effect.

\section{Practice on the Construction of Signals and Systems Course}

\subsection{Research Work Outline}

Although the basis of circuit analysis, signal and system, digital signal processing course teaching core, has reached a consensus in the domestic, but according to what order to explain, additional in what context to explain, how to carry out the teaching practice link, different materials still have different focus even quite different view of teaching, students in learning these lessons feel easy to understand the concept, but how to use the concept and theory to solve the problem is more difficult to master. According to the research content, the research work of this thesis adopts the theory - Practice Theory - Practice - Research program.

The specific process is as follows:

Theory. 
The core content of combing the logical relationship: on the continuous and discrete transforms the lecture sequence.

Select the core content of the focus: the focus of the Laplace transform to explain.

Experimental content and timing considerations: learn the signal and system, practice is the essential link, in practice, the MATLAB software is the most important tool. This software is separate experiment course is arranged in after-school exercise.

Practice.

In the 2015 to 2016 academic year second semester courses are set up to carry out the teaching practice, the application of different professional cases into the professional characteristics, this semester has been considered based on MALBA software for experimental teaching.

Research.

In the summer of 2016, in Shanghai local institutions and / or Nanjing, Beijing, Xian, Wuhan and other relevant institutions, in the related curriculum syllabus, teaching methods and means and the contents of, and majors, teachers of on-the-spot investigation and study.

Theory.

Summed up the research content, learn from each other, combined with the teaching practice of the school and the relevant institutions of the teaching theory and practice experience, prior to the theoretical study of the amended. The interim results for submission at least one teaching reform based on writing research reports on.

Practice.

Summary of open class of the signal and system course teaching practice in 2015 and 2016 and the second semester of the academic year, in the first semester of the academic year 2016 and 2017, open class of the signal and system course further teaching practice, writing papers on teaching reform.

\subsection{The Foundation of Research Work and Data Preparation}

Through the investigation of multiple schools, a variety of teaching materials, and the study of multiple teaching materials, this research group has been thinking and / or pre research on the following questions:

Continuous transformation and discrete transformation of the lecture sequence.

Laplace transform to explain the focus.

The use of MATLAB software.

Signals and systems to learn, practice is the essential link, in practice, the MATLAB software is the most important tool, this semester of this software mainly to separate experiment course based, arrange in after-school exercise as a supplement.

The classic examples of the application.

Classic example based, supplemented by lectures and update part of the line with the modern background of examples, explain in the interest and in explain interest.

The experimental form of selection.
Experiment is an essential part of teaching, the demonstration experiment emphasizes on the principle explanation, the research experiment emphasizes on improving the students' ability to analyze and solve problems. Organic combination of the two.

There are a number of research papers related to the reference, the domestic and foreign classic materials, such as the Massachusetts Institute of Technology (MIT), the United States Oppenheim prepared Xi'an Jiaotong University's translation of the classic textbook, problem sets and experimental guide books several versions.

\subsection{Research Plan}

Basic circuit analysis, signal and system, digital signal processing is a combination of theory and practice, the application of a wide range of cross penetration of many subjects.

The signals and systems is to the engineering properties of signals and systems and signal processing as the background, and formed by abstraction of mathematics and theoretical generalization of a course, anything can regarded as a system, system model was established and the system analysis theory, carries on the quantitative analysis. Therefore, the concept of analysis used in this course is an important part of many engineering disciplines.

Understanding of the relevant university, including 985, 211 of the training objectives of the course, teaching syllabus, teaching content and the contents of; $\mathrm{AC}$ for different disciplines, the course of basic teaching requirements; understanding for to cultivate application ability as the main target of the school. The curriculum teaching emphasis.

Learning and exchange of the course on the evaluation of students' learning effects, classroom teaching methods, teaching content, the key and difficult way to deal with.

To learn about the situation of teaching teachers and the measures of team building, and to understand the evaluation method of the teaching ability and teaching effect of the school.

In the first half of 2016 :

Foreign language teaching materials and the selection of Chinese Textbooks: foreign language teaching materials to help the advantages of reading and writing, Chinese teaching materials have the advantage of helping to understand.

Class teaching and group discussion: in the process of teaching, the class teaching, group discussion to form complementary.

Writing research papers.

Summer 2016:

Related colleges and universities research, the curriculum teaching outline, teaching methods and means, the experimental content, as well as the creation of professional, teaching teachers and other conditions of the field investigation and study.

Research software and hardware experiments, there are many schools in the MATLAB based on the increase of FPGA experiments to further verify the theoretical knowledge of the real environment, there are many schools 
still insist on software verification.

Writing research reports.

In the second half of 2016 :

The new teaching idea, method, case and so on is applied in the actual teaching.

On the basis of previous studies, writing teaching and research teaching reform papers, to carry out the investigation of the effect of practice.

\subsection{Research Results and Use Range}

To integrate the core of teaching content.

Considering the former student order course of complex variable function understanding may not thoroughly, three transform parallel explanation mode for serial explaining mode, that is, let the students truly grasp the Fourier transform, and Fourier transform based, lets the student understand other transformations. Also as a result of the former course complex variable function course students may understand the lack of thorough, add zero pole content teaching, because this aspect of the analysis of the follow-up courses are very helpful, such as digital signal processing, etc..

To adjust the content of the exercise and strengthen.

To students currently on the formula is more formal understanding and understanding is not a concept, so in the operation of layout problem of MATLAB programming and drawing, students through MATLAB drawing, you can visually understand the formula to express the physical meaning is taken into account. Examples using considering signals and systems is the basic course for subsequent course foreshadowing, to different professional follow-up courses in the practical application, based on the corresponding explain examples.

The results will be applied to the Shanghai Dian Ji University of electronic information engineering, communication engineering, computer applications, networking, networking, automation, vehicles, cars and other professional courses in teaching practice.

\section{Conclusion}

Signals and systems is a very important professional basic course in electronic information specialty. In this paper, based on the position of technology applied university, the signals and systems course construction is planned, the relationship and interaction between theory and practice teaching are thought, and the course construction goal, content, principle, method, practice process and characteristics are presented.

Our group is mainly for domestic and foreign universities research teaching status of a profession Signals and Systems, integrate the school's electronic information engineering, a number of professional communications engineering, networking, network, computer, automation, automotive, vehicles have set up signal and present course system, focusing on common and individual features of the professional course, highlight the core content on the commonalities, the outstanding characteristics of different professional application cases, while maintaining the common, prominent features.

In summary, the study and practice of Signals and Systems course, instructors can improve their teaching and promote students Signals and Systems to understand and master the core content, improve their theoretical and practical ability to bind; in favor of signals and systems course in the application of multi-disciplinary teaching technical colleges, lay the foundation for the subsequent construction of excellent course signals and systems. This course construction can really improve the teaching effect.

\section{Acknowledgements}

This work was supported by 2016 Shanghai Dianji University Leading Courses Construction on Signals and Systems and 2016 Shanghai Dianji University Leading Teaching Research and Reform Projects on Reform and Practice on the Teaching of Professional Basic Course Group in the Wide Field.

\section{References}

[1] Zheng Junli and Gu Yuantao, "Signasl and systems history and evolution," Journal of electrical and electronic teaching, 2012, 34 (2), pp. 1-6.

[2] Chen Houjin et al., "Reform and construction of signal and system course in our university," Journal of electrical and electronic teaching, 2004, 26 (6), pp. 30-32.

[3] Li Yuanlu, "Thinking and practice of the teaching reform of the signasl and systems course," China electric power education. 2009, (131), pp. 42-43.

[4] Li Jianhua, Ma Xiaohong, and Qiu Tianshuang, "Analysis of the course system of signals and systems," Journal of electronic and electronic teaching," 2010, 32 (2), pp. 14-17.

[5] Liu Hongsheng, Zhu Xueyong, and Pengqizong, "Digital signal processing and signals and systems two courses of overlap content processing method discussion," Journal of electrical and electronic teaching, 2004, 26 (6), pp. 40-42.

[6] Bi Ping and Liu Yu, "Excellence Engineer target teaching reform of the course of signals and systems," Laboratory research and exploration, 2014, 33 (1), pp. 190-193.

[7] Liu Feng et al., "Experimental teaching reform of signals and systems," Experimental technology and management, 2008, 25 (3), pp. 118-120.

[8] Zhang Lihong and Zhou Ziang, "Discussion on signals and systems teaching reform in colleges and universities," 2010, 27 (5), pp. 69-71.

[9] Huang Zailu, Introduction to Electronic Information Science and Technology, Higher Education Press, 2011.

[10] Shi Dongcheng, Introduction of Information and Communication Technology, Tsinghua University Press, 2011.

[11] Ye Shujiang, Introduction to electronic information engineering, China Electric Power Press, 2012. 
[12] Yang Jie, Introduction to Electronic Information Engineering, Electronics Industry Press, 2010.

[13] Li Yanda, Introduction on Information Science and Technology, Tsinghua University Press, 2005.

[14] Peng Wenkun, "Matlab in signal and system analysis," Electronic technology and software engineering, 2016-01-26.

[15] Zhang Lianlian, Guo Wei, and Long Zaiyun, "Project approach applied to the signal processing course of study and practice,"Western Education, 2016-03-25.

[16] Liu Ling, Wang Linna, and Liu Ding, "Teaching reform and practice of signal analysis and processing," Horizon Science and Technology, 2016-04-05.

[17] Qu Na, "Signals and systems experiment teaching reform and exploration," Communications World, 2016-03-25.

[18] Xiao Lin, Zhang Yongsheng, and Liu Pei, "Western region rignals and systems theory and practice of curriculum teaching Method," Horizon Science and Technology, 2016-01-15.
[19] Po Fangling, Xu Xin, and Zou Lian, etal., "Oriented innovative ability and teaching reform signal system," Computer Education 2016-01-10.

[20] Wang Ting, "Signals and systems course of process thought and improvement," Horizon Science and Technology, 2016-01-25.

[21] Xiao Lin, Zhou Wenhui, and Jin Jie, "Western region signal and system experiment teaching reform and exploration," Asia-Pacific Education, 2016-02-15.

[22] Linjun Wu, "Signals and systems applied universities teaching reform," Yulin College, 2016-03-15.

[23] Chi Yaodan, Wang Chao, and Gao Xiaohong, "Electronic information basic course curriculum construction," Management \& Technology, 2016-01-15.

[24] Xu Chunyu, Wang Yufeng, and Guo Changying etal., "Signal and system exploration teaching reform," Modern Computer 2016-01-05. 